\title{
POLÍTICAS DE EDUCAÇÃO E SAÚDE FRENTE ÀS METAMORFOSES DO SISTEMA CAPITALISTA PARA EXPANSÃO NEOLIBERAL.
}

\section{EDUCATION AND HEALTH POLICIES IN FACE OF THE METAMORPHOSIS OF THE CAPITALIST SYSTEM FROM NEOLIBERAL EXPANSION.}

Vanessa Gomes da Silva ${ }^{1}$

\section{RESUMO}

O texto faz um resgate histórico e organiza elementos que compõem as ciências sociais para entender a realidade. Desde a crítica da economia política desenvolvida por Marx no século XIX, até a atualidade nos anos dois mil, com a política neoliberal e as metamorfoses do sistema capitalista para uma continuidade na extração de mais valia com uma nova roupagem. Esta atualização do arcaico é a condição fundamental para a expansão neoliberal, pois, agrega novos pressupostos como: flexibilidade e cooperação social. A discussão provoca alternativas de superação e aponta a necessidade de um movimento na educação e na saúde que busque a reflexão e a crítica, para organizar diretrizes que permitam a emancipação do cidadão.

PALAVRAS-CHAVE: Educação - Saúde - Política Neoliberal.

\section{ABSTRACT}

The text presents a historical rescue and organizes elements that comprise the social sciences to understand reality. Since the critique of political economy developed by Marx in the XIX century until today in two thousand years, with neoliberal policies and the metamorphoses of the capitalist system to a continuity in the extraction of surplus value with a new package. This update if the archaic is the fundamental condition for the expansion of the expansion of Neoliberal therefore adds futher assumptions such as: flexibility and social cooperation. The discussion leads to alternatives to overcome 
and highlights the need for a movement in education and health that seeks to reflect and critique, to organize guidelines whereby the emancipation of the citizen.

KEYWORDS: Education - Health - Neoliberal Policies.

\section{INTRODUÇÃO}

Nas Ciências Sociais diversos determinantes como: política, ideologia, economia, saúde, trabalho, educação e tantos outros estão imbricados na contextualização da sociedade. Que por sua vez é constituída por indivíduos divididos em classes sociais que identifica a divisão social do trabalho. Com a Crítica da Economia Política de Marx no século XIX consolida a reflexão sobre O Sistema Capitalista, suas formas de produção e expropriação do trabalhador. A reflexão sobre concepções de mundo e verdade que 'socialmente' são construídas como absolutas no processo de dominação que gerencia as práticas sociais.

$\mathrm{Na}$ historicidade do desenvolvimento das sociedades o dinheiro desde a antiguidade desenvolve uma relação unilateral as nações comerciais. O sistema monetário situa a riqueza no dinheiro. Como isso à generalidade atribuída ao trabalho acarreta uma indiferença em relação às especificidades de cada trabalho. Desta forma os indivíduos podem desenvolver múltiplas atividades, podendo o trabalho ser organizado em categorias, que pretendem produzir riquezas em geral. A divisão social do trabalho caracteriza uma condição de dominação onde o trabalhador é submetido às exigências do sistema de produção e de quem os detêm. O capital neste sentido compõe um conglomerado: trabalho assalariado, modos de produção, extração de mais valia, dentre outros determinantes inerentes ao modo de produção capitalista.

A divisão do trabalho é a expressão econômica do caráter social do trabalho no interior da alienação. Ou, posto que o trabalho não é senão um expressão da atividade humana no interior da alienação, da exteriorização da vida como alienação da vida, assim também a divisão do trabalho nada mais é do que o pôr alienado, alheado da atividade humana enquanto atividade genérica ou como atividade do homem enquanto ser genérico. (MARX, 1987:190) 
Marx (1987) destaca que a relação entre modos de produção e a sociedade burguesa historicamente se articulam, logo, o desenvolvimento histórico da economia burguesa considera 'as etapas' como seu próprio grau de desenvolvimento não refletindo e muito menos criticando sua organização, sendo assim unilateral. Na sociedade burguesa a agricultura se transforma em simples ramo da economia que é dominada completamente pelo capital o que na antiguidade a agricultura predominava. E o capital (sem ser simples dinheiro) na Idade Média era configurado como "propriedade fundiária".

Estas premissas orientam a discussão aseguir, pois o eixo estruturante deste texto relaciona o Neoliberalismo como estratégia do Estado para favorecer as relações de mercado e conseqüentemente trabalhistas. E cronologicamente entender ou buscar respostas para desenrolá-lo nas políticas sociais (educação e saúde) em meio às determinações econômicas.

A base capitalista de desenvolvimento impulsiona sempre a expansão territorial para as mercadorias (consumo) e investimentos que garantam retorno rápido e com custos reduzidos (empréstimos). Negociações que pretendem manter elevadas as taxas de lucro. Neste sentido o mercado organiza as relações sociais no seu envolvimento com o Estado e a população. A partir da década de setenta no século $X X$, o neoliberalismo assegura o livre mercado e a flexibilidade do trabalhador como forma necessária ao desenvolvimento.

\section{A EXPANSÃO NEOLIBERAL E A POLÍTICA EDUCACIONAL}

$\mathrm{Na}$ organização política e social o sistema capitalista embasa as relações sociais de tal maneira a desenvolver aceitação passiva da população, pois os modos de produção da existência são únicos e imutáveis pela hegemonia capitalista. Esta passividade hierarquizada e antidemocrática acaba sendo uma aceitação fatalista. A teoria neoliberal globalizada no século XXI está naturalizada como reguladora da ordem social. O mercado desenvolve uma 'ideologia' para organização dos negócios, da vida, do trabalho e o Estado por consenso da sociedade civil reafirma esta ideologia. 
A construção ativa do consentimento também variou de lugar para lugar. Além disso, como atestam inúmeros movimentos de oposição, o consentimento muitas vezes se enfraqueceu ou fracassou em diversos lugares. Contudo, temos de examinar, para além desses mecanismos culturais e ideológicos infinitamente variados - por mais importante que sejam - as qualidades de experiência cotidiana a fim de melhor identificar as bases materiais da construção do consentimento. (HARVEY, 2008:50)

Segundo Harvey (2008) na análise da política neoliberal através da história e seus mecanismos de atuação aponta como uma das estratégias a construção do consentimento. Pela desmedida do capital na extração de mais valia esta teoria se baseia nas premissas de favorecimento aos direitos individuais de propriedade privada e livre comércio. Assim o clima gerado é de favorecimento aos negócios e ao comércio neutralizado as classes sociais.

A liberdade comercial é também a liberdade individual de tal modo que o sujeito tem 'autonomia' para traçar sua trajetória profissional e o resultado, sucesso ou fracasso, apenas diz respeito a sua capacidade ou competência. Como se o sujeito estivesse neutralizado do mundo e os determinantes sociais, históricos, políticos e econômicos pudessem se desarticular da vida social. $\mathrm{O}$ indivíduo encapsulado produz meios para sua existência e compõe a 'organização social' a qual estamos todos envolvidos, onde há um conjunto coerente de valores morais. E em caso de 'insucesso profissional' a culpa é única e exclusiva do sujeito.

Para o mercado de trabalho a 'flexibilidade' é a condição primordial ou qualidade essencial para o trabalhador 'competente'. O trabalhador frente ao domínio do mercado apresenta-se em desvantagem. O capital pode apropriar-se da especialização flexível como maneira conveniente de buscar formas mais flexíveis de acumulação. Essas duas expressões, especialização flexível e acumulação flexível têm conotações bem diferentes. $O$ resultado geral se traduz em baixos salários e, crescente insegurança no emprego e, em muitos casos, perda de benefícios e de proteções ao trabalho. (HARVEY, 2008:86).

Seguindo a linha do projeto neoliberal as formulações educacionais têm papel fundamental para estimular a competição, aflorar as potencialidades e educar para o mercado. Logo, a tendência é o individualismo como ferramenta fundamental que justifica a competitividade e o empreendedorismo. O Brasil como país periférico, economicamente dependente, seguiu e ainda segue as diretrizes internacionais em 
toda conjuntura política. De maneira subordinada aos interesses capitalistas, se acomoda e reproduz estratégias de conformação social.

O capitalismo dependente a que o Brasil é submetido caracteriza a burguesia brasileira como 'sócia minoritária' e a burguesia internacional dos países centrais são os 'acionistas majoritários' que formulam as diretrizes dos processos educativos e formativos para os trabalhadores na divisão internacional do trabalho. Que para os países dependentes implica a subordinação do trabalhador, das relações de trabalho, precariedade dos vínculos empregatícios.

O sistema de produção capitalista preserva-se na atualidade pela idéia de 'livre mercado' e mesmo com características históricas, sociais e culturais diferentes entre os países o projeto neoliberal cria condições políticas para implementação do programa de Terceira Via. Em meio à 'ausência' de possibilidades políticas cabe a sociedade o compromisso 'ético e moral' de agir em prol da humanidade tornando o capitalismo menos perverso.

Martins (2009) desenvolve bases teóricas sobre idéias e concepções que consolidam o projeto neoliberal para a revisão da sociabilidade capitalista. A primeira aponta para a importância do 'mercado' na sociabilidade e a subordinação das relações sociais e historicidade. Segundo aspecto importante é o individualismo como valor moral radical, a falsa idéia de liberdade que enfraquece as classes trabalhadoras e favorece a competição. Terceiro ponto segue este raciocínio pela falsa idéia de autonomia a liberdade como direito natural. O Estado neste contexto assume o 'discurso' em torno dos direitos universais e naturais, estando imune a interesses particulares.

Esta teoria é organiza em esferas ou eixos: um eixo as relações econômicas representadas pelo Mercado, em outro eixo o Estado Necessário, como esfera de poder legítimo que estabelece regulações e diretrizes para as questões econômicas e sociais e o Terceiro Setor como local de cooperação social, todos eles se relacionam na política neoliberal. Neste sentido a Terceira $V_{i a}^{2}$ reduz a condição humana de sujeito histórico que o homem é constituído e constituinte no processo das relações sociais, pois, está limitada a desenvolver estratégias de aporte ao Estado, através de programas, voluntariados, hegemonia ideológica para minimização da pobreza. Deste modo cria-se uma concepção acrítica da realidade. 
É importante considerar que um modo de produção da existência humana só existe quando as relações sociais asseguram a unidade entre o econômico e o político numa mesma direção. Com o capitalismo isso não é diferente. As relações sociais capitalistas produzem a existência humana a partir de diferentes mediações, entre ales, pela produção de mercadorias, pela divisão de homens e mulheres em classes e frações de classes, pelas formas de organização política e pela sociabilidade. Considerando a especificidade do capitalismo, a chamada "sociedade civil ativa" da Terceira Via, expressão do espaço da colaboração, do ativismo social e das individualidades, é na verdade uma apreensão abstraída do mundo real em que vivemos, por isso, somente alterações parciais nas relações de poder não podem ser interpretadas como alteração nas relações sociais em seu conjunto, como sugere a Terceira Via (MARTINS,2008:26)

E para organizar e difundir este ideário de progresso e união que abre possibilidade para o desenvolvimentismo os intelectuais orgânicos do capital e da política neoliberal exercem o poder nas sociedades de classes através da nova pedagogia da hegemonia ${ }^{3}$ Neves (2010) relaciona a formação e atuação dos intelectuais orgânicos da nova pedagogia da hegemonia com o projeto de dominação e adaptação aos interesses da sociedade capitalista.

A construção de uma concepção de mundo adequada ao contexto do novo imperialismo no Brasil vem, portanto, demandando à classe dirigente/dominante a formação de uma nova camada intelectual via uma escolarização e uma formação política renovadas. Desse modo, a construção de uma nova sociabilidade pautada na participação como colaboração de todos em prol de uma harmonia social vem-se dando sob a batuta de Estado educador, em duas frentes fundamentais: a educação política, difundida pela crescente atuação social empresarial no país, e a educação escolar das novas gerações de trabalhadores e cidadãos brasileiros (NEVES, 2010:86).

O perfil destes intelectuais é 'alinhado' conforme as necessidades do mercado para que o processo pedagógico aplicado aos trabalhadores e futuros trabalhadores incorpore conhecimentos e técnicas para o manejo das novas tecnologias do mundo moderno. Educação em massa e formação para articular habilidades e atitudes na reprodução da pedagogia das competências. É a adaptação contínua dos homens ao mercado, novos meios de produção e novos postos de trabalho (ocupações ${ }^{4}$ ).

A educação escolar compromete-se em difundir uma identidade políticoideológica que sustentam o capitalismo para a formação pautada nas competências profissionais. Esta noção vai além da educação básica é no século XXI componente essencial curricular dos diversos cursos de formação profissional. 


\section{AVANÇOS E RETROCESSOS DAS POLÍTICAS DE SAÚDE}

Para a formação dos profissionais de saúde cabe destacar a mecanização do trabalho como problemática estrutural de uma formação aligeirada, desprovida de embasamento científico e reflexão crítica do contexto social. E no final de século XX e início do novo século, novos 'programas de formação' foram reconfigurados e norteados pela pedagogia das competências. O contexto de Reforma Sanitária ${ }^{5}$ da década de oitenta e consolidação das Leis do Sistema Único de Saúde ${ }^{6}$ (SUS) pautados no olhar ampliado de promoção, proteção e recuperação da saúde não foi suficiente para a garantia da saúde como um direito de todos e dever do Estado.

Este 'novo olhar' para a saúde pautado na reformulação administrativa, organizacional das instituições e atualização profissional objetivou a implementação de um modelo igualitário, amplo e digno para todos. Concomitantemente os projetos econômicos, políticos e sociais estão em disputa na arena global capitalista. Esta interferência fragmenta a formação dos trabalhadores em todos os níveis.

As políticas de saúde legitimam as ações de saúde (assistência, prática, educação e gestão), mas não asseguram o cumprimento das mesmas. Uma desarticulação entre teoria e prática que na realidade provocam implicações para os trabalhadores e usuários.

A educação em saúde em uma perspectiva emancipatória integra o conteúdo teórico com a vivência prática, assim busca contribuir para um envelhecimento digno na valorização da assistência. Na tentativa de promover a autonomia do trabalhador, através do embasamento teórico de sua prática e das políticas e realidade social. Para que tenha a oportunidade de agir como protagonista no desempenho de suas atividades ocupacionais. A integração de todas estas atribuições torna-se um desafio potencial para o sistema formativo. Mas em outra vertente o mercado direciona a formação, pela adequação do trabalhador as exigências para empregabilidade.

$\mathrm{Na}$ formação profissional a preocupação transita pela hegemonia capitalista de produtividade e flexibilização do trabalho no campo organizacional do processo formativo. Que conseqüentemente produzir um sentido muito adequado ao trabalho no capital e à educação que não desenvolve a emancipação e não funciona 
como resistência. E sim uma educação que podemos dizer que não cumpre o seu papel, de questionar e buscar autonomia.

Este processo de Reforma buscou romper com a prática mecanicista e intervencionista, por valorizar o sujeito em meio seu ambiente social, na promoção, proteção e recuperação da saúde. Logo, em meio a novas diretrizes e organização do sistema de saúde era necessário que o futuro profissional e o profissional de saúde já atuante fossem capacitados para acompanhar as mudanças estruturais. Seguindo esta lógica cabe o trabalho em saúde é coletivo, interdisciplinar e multiprofissional no sentido amplo que corresponde a um trabalho 'vivo' que depende da interação de profissionais da mesma categoria ${ }^{7}$ e de outras categorias profissionais. O processo educacional neste sentido pretende ampliar os conhecimentos técnicos e científicos, para que sejam revertidos em uma melhor assistência em saúde, e consequentemente favoreça a articulação dos diversos profissionais da área de saúde.

$\mathrm{Na}$ esfera pública juntamente com este movimento duas propostas educacionais que partiram da crítica ao processo mecanizado, surgiram e na consolidação do processo pedagógico seguiram vertentes diferentes: $O$ Larga Escala e a Fundação Oswaldo Cruz - Escola Politécnica de Saúde Joaquim Venâncio (EPSJV).

O Projeto Larga Escala atuou na formação 'em massa' dos trabalhadores no interior dos setores de saúde, capitaneado pela valorização da integração ensinoserviço, na prática profissional. Desta forma as competências profissionais ganham destaque para empregabilidade no desenvolvimento dos conhecimentos, habilidades e atitudes convergidos ao sistema produtivo.

$\mathrm{Na}$ outra vertente a EPSJV com a proposta de politecnia ${ }^{8}$ pretende superar a mecanização do trabalho a partir da ênfase no conhecimento científico e sua articulação com a realidade social. A crítica ao processo de trabalho alienado e

a formação aligeirada são vertentes essenciais para a organização do projeto político pedagógico.

Portanto, a noção de politecnia se contrapõe a uma concepção de profissionalização que tem como pressuposto a fragmentação do trabalho em especialidades autônomas, a divisão entre os que executam e aqueles que concebem e controlam o processo de trabalho, e a polivalência do trabalhador que domina uma multiplicidade de técnicas fragmentárias. Ao contrário, 
postula que o processo de trabalho desenvolva uma unidade indissolúvel entre os aspectos manuais e intelectuais e que o trabalhador domine os fundamentos científicos das diferentes técnicas da produção moderna no ensino médio. Não se trata de formar um trabalhador adestrado para executar determinada tarefa requerida pelo mercado de trabalho, mas na perspectiva de um desenvolvimento multilateral em todos os seus aspectos: físico, intelectual, prático, político, ético, estético, combinando estudo e trabalho.(LIMA, 2010:129)

Neste contexto a educação, contribui para a emancipação dos trabalhadores em contraposição a uma ordem social e econômica excludente. Tratase da possibilidade de formar profissionais em um processo onde se aprende praticando, mas ao praticar, se compreendem princípios científicos que estão direta e indiretamente na base desta forma de organizar o trabalho na sociedade.

$\mathrm{Na}$ realidade esta proposta enfrenta obstáculos, por ser uma alternativa de superação a imobilização dos educadores e da sociedade. Como proposta emancipatória do homem na sociedade capitalista, esta iniciativa que integra educação e trabalho na área da saúde, buscar romper com a mecanização e subordinação do trabalhador.

\section{CONCLUSÃO}

No panorama internacional e globalizado - O Relatório Mundial de Saúde 2008, intitulado: Cuidados de Saúde Primários - Agora Mais Que Nunca, traz o questionamento sobre a necessidade de implementar reformas para atender o crescente desenvolvimento mundial. As reformas apontam para: reformas da cobertura universal, reformas de prestação de serviços, reformas de lideranças e reformas políticas públicas. No mínimo torna-se ingênuo pensar em ações pontuais na área da saúde, como se estivesse neutralizada frente aos interesses de dominação que permeiam toda nossa vida social.

Estas reformas da prestação dos serviços têm o intuito da transformar a prestação tradicional de cuidados de saúde em cuidados primários, otimizando a contribuição dos serviços de saúde - sistemas locais, rede de cuidados de saúde, distritos de saúde - para a saúde e equidade, enquanto respondem às expectativas crescentes de "colocar as pessoas no centro dos cuidados de saúde, harmonizando a mente e o corpo, as pessoas e os sistemas (OMS, 2008) 
No campo da saúde a mercantilização de serviços e produtos na perspectiva lucrativa e econômica pode ser entendida como: 'capitalização da medicina' que reflete negativamente na formação profissional e no acesso dos usuários. Este processo é identificado por Lima (2010) desde o século passado e mesmo com a Reforma Sanitária e a consolidação do SUS na década de oitenta do século $X X$ as premissas de direitos universais e ênfase em cuidados primários, sofrem interferências dominantes do mercado pela valorização do uso de medicamentos e internação para realização de procedimento invasivos como: cirurgias, exames, dentre outros, e o hospital predomina como eixo estruturante destas relações.

As políticas educacionais legitimam a livre iniciativa do sistema privado e em alguns programas como o ProUni (Programa de Universidade para Todos), financiam diretamente a expansão deste sistema através da sustentação de vagas. A falta de investimento no ensino público abrange todo o sistema desde a educação básica até o ensino superior, além disso, o investimento de pesquisa na saúde e educação para a formação de mestres e doutores.

Logo, na prática da vida social as possibilidades são reduzidas e o homem limita-se a registrar uma realidade que se processa 'independentemente'. É a consolidação do pensamento que se remete a uma filosofia (concepção de mundo) que ideologicamente se regula a uma norma para desenvolvimento da concepção dominante. E esta ideologia apresenta uma ética correspondente para influenciar o pensamento e comportamento do homem socialmente. Que obviamente reduz o conhecimento.

Ainda que a escola no capitalismo sofra influência preponderante da concepção de mundo burguesa e das necessidades da reprodução da força de trabalho, ela, desde os seus primórdios, vem se constituindo também em demanda da classe trabalhadora para o exercício de tarefas simples e complexas na produção da vida e também para a compreensão das relações sociais historicamente constituídas e do seu lugar nessas relações. A escola pode ser útil à classe trabalhadora como instrumento de barganha por melhores condições de trabalho, como instrumento de alargamento do grau de conscientização política e como instrumento da formulação de uma concepção emancipatória das relações sociais vigentes. Mas, para que a educação escolar se transforme efetivamente em instrumento da conscientização de classes, ela precisa superar a sua sempre crescente subsunção aos imperativos técnicos e ético-políticos da mercantilização da vida, privilegiando na sua estruturação curricular a omnilateralidade e politecnia.(NEVES e PRONKO, 2008:29) 
Um processo de reforma implica a articulação com diversos 'atores' para repensar conceitos e programar mudanças. O questionamento é como podemos agir de maneira contra-hegemônica? Ir além da teoria, propor estratégias e conseguir implementar mudanças. Essa inquietação é freqüente e compõe a reflexão e pensamento crítico na busca de alternativas opostas à dominação e alienação social.

O trabalho perpassa e constitui um conjunto de relações sociais, é uma ação humana que constrói elementos concretos e significados para a vida. Através da reflexão e crítica da realidade as 'possibilidades' ou 'alternativas' ganham significados substanciais para possíveis mudanças. Os conhecimentos advindos do processo pedagógico alicerçam a possibilidade de construção da conscientização das classes. Esta dinâmica articula trabalho e educação como premissas essenciais para construção da vida social com igualdade de oportunidades e justiça.

\section{REFERÊNCIAS BIBLIOGRÁFICAS}

BRASIL, Ministério da Saúde. Lei n 8.080, de 19 de setembro de 1990. Sistema Único de Saúde. Brasília. 1990.

. Lei no 8142 de 28 de dezembro de 1990. Sistema Único de Saúde. Brasília. 1990

HARVEY, David. O neoliberalismo História e implicações. São Paulo. Editora Loyola. 2008.

MARTINS, André Silva. A direita para o social: a educação da sociabilidade no Brasil contemporâneo. Juiz de Fora: EFJF, 2009.

5.MARX, Karl. O Capital. Manuscritos econômico-filosóficos e outros textos escritos. Terceiro Manuscrito - Propriedade privada e trabalho. 4 ed. São Paulo: Nova Cultural, p.169-200. 1987. 
NEVES, Lúcia M.W. A direita para o social e a esquerda para o capital. Intelectuais da nova pedagogia da hegemonia no Brasil. São Paulo, Xamã, 2010.

NEVES, Lúcia M.W; PRONKO, M. A. O mercado do conhecimento e o conhecimento para o mercado: da formação para o trabalho complexo no Brasil contemporâneo.

Rio de Janeiro: EPSJV. 2008.

OMS. Relatório Mundial de Saúde 2008. Cuidados Primários em Saúde: Agora mais que nunca - Introdução e visão geral. Publicado pela Organização Mundial da Saúde em 2008 sob o título: The World Health Report 2008 : Primary Health Care Now More Than Ever. Disponível em: <http: //www.who.int/.>. Acesso em 24/09/10.

LIMA, Júlio César F. Reforma sanitária e o debate em torno da formação profissional dos trabalhadores técnicos de saúde. In: Política de Saúde e Formação Profissional dos Trabalhadores Técnicos de Enfermagem. Tese de Doutorado. p.118-149. 2010.

SAVIANI, Demerval. Trabalho e educação: fundamentos ontológicos e históricos. Revista Brasileira de Educação, janeiro-abril. v.12, n. 034. Associação Nacional da Pós-Graduação e Pesquisa em Educação, São Paulo, Brasil. p.152-165. 2007.

\footnotetext{
Vanessag 2005@yahoo.com.br, Mestranda da FIOCRUZ, Escola Politécnica de Saúde Joaquim Venâncio (2010), Especialização em Educação Profissional em Saúde - EPSJV (2009), Atividade atual - Categoria Enfermagem no Ministério Ciência e Tecnologia (INCA / RJ) e Docente na área de enfermagem em nível médio. 2 "[...] Várias formulações políticas foram aperfeiçoadas a partir de experiências concretas de governos e de aparelhos provados de hegemonia. $O$ resultado foi à concretização de um programa que renovou a concepção de sociedade do neoliberalismo para o século XXI. Embora tenha sido nomeado por seus intelectuais de 'Terceira Via', outros seis termos também foram empregados com certa freqüência para denominá-lo. São eles: 'centro radical', "centroesquerda", "nova esquerda", "nova social-democracia”, "social-democracia modernizada", "governança progressiva". (MARTINS, 2009:62) 3

A nova pedagogia da hegemonia materializou-se com ações efetivas na aparelhagem estatal e na sociedade civil nos finais do século $X X$ e nos iniciais do século $X X I$, configurando uma nova dimensão educativa do Estado capitalista. Sua principal característica é assegurar que o exercício de dominação da classe seja viabilizado por meio de processos educativos positivos. (NEVES, 2010:24) 4 A Classificação Brasileira de Ocupações - CBO, instituída por portaria ministerial nº. 397, de 9 de outubro de 2002, tem por finalidade a identificação das ocupações no mercado de trabalho, para fins
} 
classificatórios junto aos registros administrativos e domiciliares. Os efeitos de uniformização pretendida pela Classificação Brasileira de Ocupações são de ordem administrativa e não se estendem as relações de trabalho. Já a regulamentação da profissão, diferentemente da CBO é realizada por meio de lei, cuja apreciação é feita pelo Congresso Nacional, por meio de seus Deputados e Senadores, e levada à sanção do Presidente da República. Disponível em:

http://www.mtecbo.gov.br/cbosite/pages/home.jsf

${ }^{5}$ Efervescência política no final da década de 70 por movimentos sociais na luta contra ditadura e para a mudança do modelo 'médico-assistencial privatista' de saúde para um modelo universal, público, descentralizado de poder e de qualidade. 6

Composto por duas Leis Orgânicas: ํㅛ 8080 de 19 de setembro de 1990 - Dispõe sobre as condições para a promoção, proteção e recuperação da saúde, a organização e o funcionamento dos serviços correspondentes e dá outras providências. E no 8142 de 29 de dezembro de 1990 - Dispõe sobre a participação da comunidade na gestão do Sistema Único de Saúde e sobre as transferências intergovernamentais de recursos financeiros na área da saúde e dá outras providências. 7 Por exemplo, a interação da equipe de enfermagem para realização da assistência e a continuidade da assistência com outras categorias profissionais: médicos, fisioterapeutas, nutricionista, dentre outros (relacionamento multiprofissional).

8i "Politecnia significa, aqui, especialização como domínio dos fundamentos científicos das diferentes técnicas utilizadas na produção moderna. Nessa perspectiva, a educação de nível médio tratará de concentrar-se nas modalidades fundamentais que dão base à multiplicidade de processos e técnicas de produção existentes." (SAVIANI, 2007:161).

RECEBIDO EM 27.09.2010

APROVADO EM 18.10.2010 